\title{
Physical and Mechanical Properties of Composites Based on Polypropylene and Timber Industry Waste
}

Research Article

\author{
Janis Kajaks ${ }^{1 *}$, Karlis Kalnins ${ }^{1}$, Sandris Uzulis ${ }^{2}$, Juris Matvejs ${ }^{2}$ \\ 1 Department of Polymer Materials Technology, Riga Technical University, P. Valdena street 3, LV-1048, Riga, Latvia \\ 2 MNKC SIA, Dzerbenes street 27, LV-1006, Riga, Latvia
}

Received 03 May 2014; accepted 27 June 2014

\begin{abstract}
Wood polymer composites (WPC) are widely used materials in different industries because of many application, processing and recycling advantages compared to traditional thermoplastic polymer composites containing mineral fillers [1]. However, the commercial success of these materials primarily depends on improvements in moisture performance, and ability to use recycled and waste material as a wood filler. The research regarding WPC is focused on the chemical interaction between dissimilar material components with an aim to provide strong adhesion to the surface of wood filler-polymer matrix [2]. The goal of this paper was to present results of investigations of exploitation properties of composites containing different plywood production industry byproducts and polypropylene. It was shown that modification of all composites with coupling agent maleated polypropylene (MAPP) considerably improve physical mechanical properties (tensile, flexural, impact strength) of WPC. MAPP ( $5 \mathrm{wt} . \%$ ) additions also significantly improve water resistance of WPC. SEM investigations confirmed positive action of interfacial modifiers on strengthening of adhesion interaction between components wood and PP matrix that give considerable increase of exploitation properties of the WPC.

Keywords: plywood industry by-products $\bullet$ polypropylene $\cdot$ composites $\bullet$ physical-mechanical properties $\bullet$ modification $\bullet$ water resistance

(c) Versita sp. z o.o.
\end{abstract}

\section{Introduction}

During the last 20-30 years, a lot of research papers have paid attention to studies of thermoplastic polymer composite materials based on natural fibres, wood flour, wood fibres and polyolefine matrices [1]. Natural lignocellulose fibres and their agriculture and textile industry waste containing polymer materials have ecological and technological advantages as opposed

*E-mail: kajaks@ktf.rtu.lv to traditional polymer composites reinforced with high modulus fibres, for example glass fibres. Natural origin fibres are environmentally friendly materials and their utilization in innovative polymer composites is defined by low cost and density, as well as practically unlimited resources in nature with very fast ability to recover [1, 2]. Polymer composites containing natural lignocellulose fibres have acceptable technological properties because polymer composite melts maintain suitable fluidity [3] that allow processing these compositions by traditional polymer processing methods like extrusion. Moreover, natural fibres do not break during processing and they do not have abrasive influence on processing equipment. 
The most popular thermoplastic polymer matrices for this purpose are polyolefines like polypropylene [4-14]. From all polyolefines, polypropylene matrix has the highest modulus of elasticity and at the same time rather low melting temperature (below $175^{\circ} \mathrm{C}$ ) that is assumed for natural fibres containing systems. Timber industry, e.g. plywood production, also generates different types of waste (by-products) which are lignocellulose containing materials like natural vegetable fibres. The aim of the present work was to approbate the utilization possibilities of three types of plywood industry by-products: birch wood plywood sanding dust (PSD), plywood sawdust (PSWD) and refined plywood scrap fibres (RPSF); to make thermoplastic polymer composites based on virgin polypropylene.

\section{Materials and investigation methods}

For preparing polymer composites the following materials were used. As polymer matrix was chosen polypropylene (PP) type Mosten MA-712 with melt flow index $\mathrm{MFI}=12 \mathrm{~g} / 10 \mathrm{~min}$. (at temperature $230^{\circ} \mathrm{C}$ ) and melting temperature $153^{\circ} \mathrm{C}$. To improve interfacial interaction between components, maleated polypropylene (MAPP) granules type Licocene PP MA-7452 (acid number 41 $\mathrm{mg} \mathrm{KOH} / \mathrm{g}, \mathrm{Tm}=159^{\circ} \mathrm{C}$ ) were used. As polypropylene thermal stabilizer served Hostanox 03P powder (from previous studies 1.5 wt.\% from PP weight was chosen), but for PP reinforcing three types of the by-products were approbated which arise in plywood production technology: plywood birch wood veneer sanding dust (PSD), plywood sawdust (PSWD) and refined plywood scrap fibres (RPSF). All these by-product types contain more fractions with different particle and fibre sizes.

PSD contain fibre fractions with length: $0.25-0.5 \mathrm{~mm}$ (68\%), 0.5-1.0 mm (16.5\%), 0.1-0.25 mm (13.6\%) and fine particles $0.04-0.1 \mathrm{~mm}(1.9 \%)$. In PSD fraction with sizes 0.25-0.5 mm (68\%) prevail. Chemical composition of the PSD: $47.8 \%$ cellulose, $20.3 \%$ lignin, $1.8-2.4 \%$ soluble substances, $0.36 \%$ mineral substance.

PSWD contain the following fractions: fibres with length $>1 \mathrm{~mm}$ (5.32\%), 0.5-1 mm (48.45\%), 0.25-0.5 mm (25.92\%), $0.1-0.25 \mathrm{~mm}$ (14.28\%), 0.05-0.1 mm (8.52\%), and dust fraction $<0.05 \mathrm{~mm}(0.48 \%)$. In PSWD fraction with fibre length $0.5-1 \mathrm{~mm}$ (45.5\%) prevail.

RPSF contain the following fractions: length $>3.25 \mathrm{~mm}$ (7.4\%), >2.9 mm (42.7\%), >0.5 mm (24.5\%), >0.063 mm $(11.3 \%)$, and dust particles $<0.063 \mathrm{~mm}(14.2 \%)$. Average length of the fibres is $0.95-1.25 \mathrm{~mm}$ and diameter 26.532.5 nanometers. In RPSF fraction with length 2.9-3.25 mm.(42.7\%) prevail. PSWD and RPSF also contain a small amount (2.0-2.4 wt.\%) of cured phenol-formaldehyde resin dusts.

Prior to mixing all by-products was dried for 12-24 h at $105^{\circ} \mathrm{C}$ in thermostat. Samples of the composites (filler content from 20 up to $50 \mathrm{wt} \%$ ) were manufactured by mixing components on two-rolls mill $\left(\mathrm{T}=170-175^{\circ} \mathrm{C}\right.$, $\mathrm{t}=10-12 \mathrm{~min}$.), then cooled, granulated (average size of the chips was 2-4 mm) and pressed $\left(T=180^{\circ} \mathrm{C}\right.$, $\mathrm{t}=5$ min., $\mathrm{P}=2 \mathrm{MPa}$ ) in $0.8-1 \mathrm{~mm}$ thick sheets for tensile strength measurements (standard ASTM D 638M). Flexural and impact strength tests were done for standard specimen (standards EN ISO-178 and ASTM D256 $M$ respectively) bars produced by injection moulding $\left(\mathrm{T}=180^{\circ} \mathrm{C}, \mathrm{P}=5 \mathrm{MPa}, \mathrm{t}=5 \mathrm{~min}\right.$.). Technological properties (fluidity) of polymer melts were estimated with melt flow index $(\mathrm{MFI})$ measurements $\left(\mathrm{T}=190^{\circ} \mathrm{C}, \mathrm{P}=2.16 \mathrm{~kg}\right.$, standard ASTM D 1238). Water resistance measurements were done according to the standard ASTM D 57088. Microstructure of the fracture surface of specimens was examined with scanning electronic microscope Vega Tescan 5136 MM. Au-sputtering was used.

\section{Results and discussion}

Our previous studies of different types of plywood production by-product influence on unstabilized virgin polypropylene physical and mechanical properties showed that investigated composites deformation ability decreases with increase of the filler content, but tensile modulus and flexural modulus increase with increase of the by-product content in polypropylene. Flexural modulus increases from $1500 \mathrm{MPa}$ for virgin polypropylene up to 2600-3400 MPa for filled systems. In addition, all composites maintain good enough fluidity: MFI values at $190^{\circ} \mathrm{C}$ change from $4.6 \mathrm{~g} / 10 \mathrm{~min}$. for virgin $P P$ till $0.6-1.11 \mathrm{~g} / 10 \mathrm{~min}$. for filled systems (filler content 40-50 wt.\%) that is sufficient to process these materials with traditional polymer processing methods. For example, the extrusion process needs fluidity of polymer melts of about $0.1-0.3 \mathrm{~g} / 10 \mathrm{~min}$., but for compression moulding it could be lower than $0.1 \mathrm{~g} / 10 \mathrm{~min}$. Bearing in mind previous experimental results, the optimal content of the fillers in composites was chosen: birch wood veneer plywood sanding dusts (PSD) in polypropylene $40 \mathrm{wt} . \%$, but plywood sawdust (PSWD) and refined plywood scrap fibres (RPSF) concentrations 50 wt.\%. Previous studies also showed that all composites are heterogeneous systems. It means that fibres have disposition to make agglomerates during mixing process and their distribution in polymer matrix is very irregular [2]. Moreover, in 


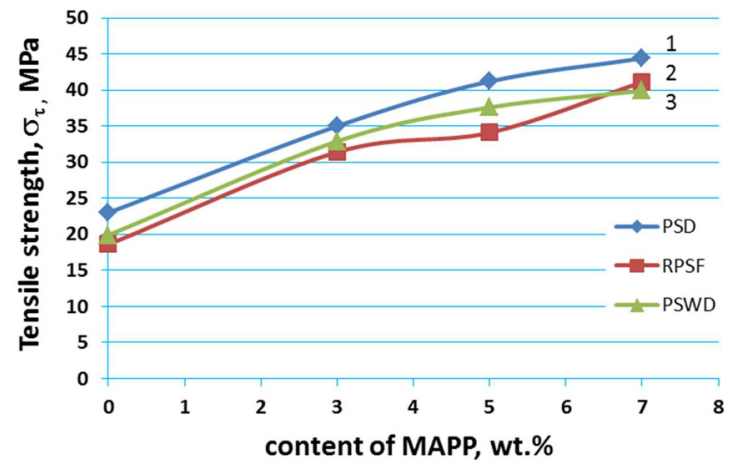

Figure 1. Dependence of tensile strength of polypropylene (PP) composites on the content of interfacial modifier maleated polypropylene (MAPP). Composites: 1-PP+40 wt.\% plywood grinding dusts (PSD), 2-PP +50 wt.\% refined plywood scrap fibres (RPSF), 3-PP+50 wt.\% plywood milling chips (PSWD). Stabilizer Hostanox $03 \mathrm{P}$ content in the composites $1.5 \mathrm{wt} . \%$.

filled unmodified polymer composites weak interaction on the surface between filler and polymer matrix is often observed [3-5]. In order to stabilize all chosen systems, promote fibres dispersion in polypropylene and improve interaction between components in presented studies, optimal compositions of the composites were stabilized with thermal and oxidation stabilizer Hostanox $03 \mathrm{P}$ (from preliminary investigations stabilizer concentration was chosen 1.5 wt.\% from PP weight) and as interfacial modifier one of the most effective and widely used for similar natural fibre containing polypropylene composites maleated polypropylene waxes (MAPP) was selected. This modifier not only improved interfacial interaction between components of the composites, but often also promoted better spread of the fillers in the volume of the polymer matrix [6-15]. The most often used concentrations of maleated polyolefin waxes as modifiers in polyolefin/wood composites are 2-8 wt.\%.

In presented studies several concentrations of the MAPP $(3,5,7$ wt.\%) influence on previous determined optimal composition of the wood/ polypropylene composites (WPC) physical-mechanical properties (Figure 1Figure 3) and water resistance (Figure 4) were approbated. Results of the SEM investigations are shown in Figure 5.

Physical mechanical properties studies (Figure 1Figure 3) showed that modification of the composites with interfacial modifier MAPP considerably increased the tensile strength (2-2.2 times, Figure 1), flexural strength (1.7-2.2 times, Figure 2) and impact strength (1.5-2.2

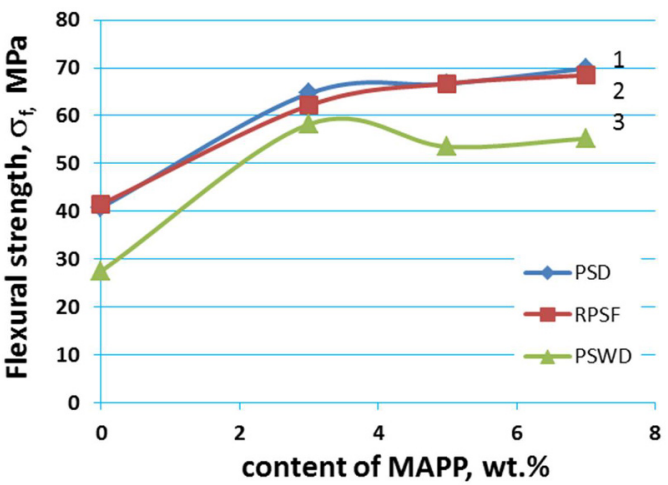

Figure 2. Dependence of flexural strength of polypropylene (PP) composites on the content of interfacial modifier maleated polypropylene (MAPP). Notations as in Figure 1.

times, Figure 3). Simultaneously, deformation ability of materials changed insignificantly compared to unmodified wood polypropylene composites (WPC) with increase of concentration of the MAPP. For example, for composite with PSD elongation at break in tensile tests fluctuates in limits 7-7.5\%, but for RPSF and PSWD containing composites $5.2-7 \%$ and $2-4 \%$, respectively. At the same time tensile modulus values increase from 800-1200 MPa for composites without modifier (MAPP) up to 1800$5500 \mathrm{MPa}$ for modified systems were observed. Flexural strength studies showed (Figure 2) that the rapid bending strength increase of the composites takes place at 3 wt.\% of content of the MAPP and then changes only insignificantly. It means that 3-5 wt.\% of MAPP additions are enough for reaching a good homogenization effect of the composites and high interfacial adhesion between components. Maximum of the bending deformation actually does not depend on the content of MAPP in systems and fluctuated in limits from $2 \mathrm{~mm}$ up to $3 \mathrm{~mm}$.

Flexural modulus of all composites like bending strength increases considerably (about 1.2-3 times) and the highest values (3000-3700 MPa) are gained at concentration of the MAPP in WPC 5 wt.\%.

Impact strength (A) tests (Figure 3) showed that $A$ numerical values considerably increase with increase of the MAPP content for all systems, but the best results were obtained for material containing PSD filler (curve 1). Impact strength can reach $13.8-14.4 \mathrm{~kJ} / \mathrm{m}^{2}$ at MAPP concentration 5-7 wt.\%. Maybe such results are obtained because PSD have the most suitable length of the fibres which is observed for similar composites [3, 9, 11, 12]. The main fraction in PSD (68\%) are fibres with length 0.25-0.5 mm, but PSWD is dominated (45.5\%) by fibres 


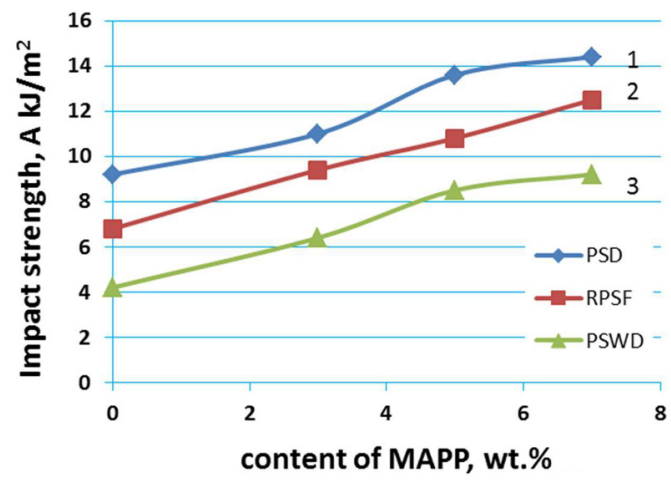

Figure 3. Dependence of impact strength of polypropylene (PP) composites on the content of interfacial modifier maleated polypropylene (MAPP). Notations as in Figure 1.

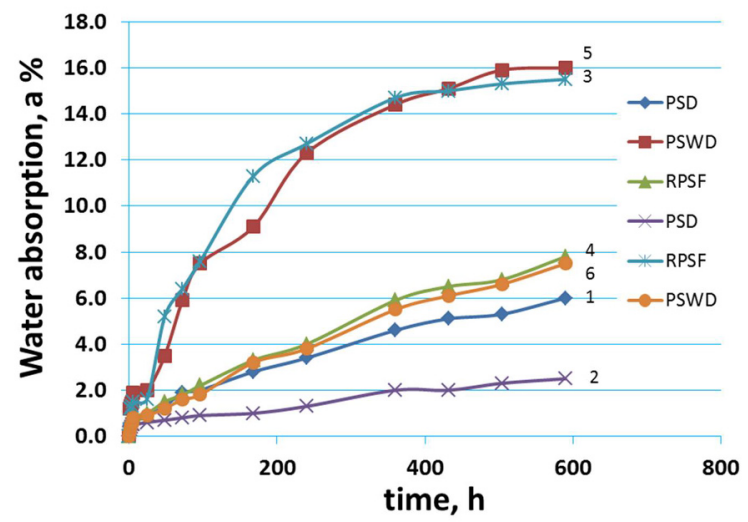

Figure 4. Water absorption kinetics of polypropylene (PP) composites. 1- PP+40 wt.\% PSD, 2- PP+40wt.\% PSD + 5 wt. $\%$ MAPP, 3- PP+50 wt.\% RPSF, 4- PP+50 wt. $\%$ RPSF +5 wt. MAPP, 5- PP +50 wt. $\%$ PSWD, 6- PP +50 wt. $\%$ PSWD +5 wt. $\%$ MAPP.

with length 0.5-1.0 mm and RPSF - by fibres with length 2.9-3.25 mm (42.7\%). Summarizing previous studies, such improvements in the physical-mechanical properties of all filled materials could be explained by decreasing heterogenity of WPC and as a result of the maleated polypropylene positive effect to increase the interfacial interaction on the surface of the fibres. MAPP also promotes better distribution of the fibres in polymer matrix $[6,10,12]$. Optimal content of the MAPP in investigated WPC could be 3-5 wt.\%.

Simultaneously with physical-mechanical properties studies, fluidity of the composite melts was also controlled.
It was done by the measurements of the melt flow index (MFI). These studies showed insignificant influence of the MAPP on fluidity of the composite melts. Only very small tendency of increase (0.6-1.2 g/10min.) in MFI values was observed which indicated that MAPP had a small plasticizing effect on the composites. Noted values of the MFI make it possible to process such polymer composites by traditional polymer processing methods as extrusion and to produce different WPC continued profiles. Adding wood to thermoplastic matrix inevitably causes an increase in moisture uptake that limits the use of these materials in exposed environments $[3,13]$. Therefore water absorption and swell experiments are very important to evaluate behaviour of wood containing thermoplastic composites at elevated moisture conditions. Results of water absorption tests are presented in Figure 4. Figure 4 shows that MAPP additions remarkably improve water resistance of all investigated composites. During $600 \mathrm{~h}$ water exposure the absorbed water amount considerably decreased from 15.5-16\% (curves 3,5) till 7.8-8\% (curves 4,6).

The best water resistance properties is demonstrated by the system consisting of PP and 40 wt.\% PSD modified with 5 wt.\% MAPP. For this composite decrease in moisture uptake is observed (3 times). Water absorption diminution from $6 \%$ (unmodified system, curve 1), till $2.2 \%$ (system modified with MAPP, curve 2) indicates that coupling agent MAPP strengthens interfacial adhesion between components. Sample thickness swelling is small in presence of the MAPP. Thickness of the samples fluctuate in the range of $1-2 \%$.

In order to clear up coupling agent influence on strengthening effect of composites and fillers distribution degree in polymer matrix, a lot of researchers use scanning electron microscopy (SEM) investigations [12, 14, 15]. Some pictures from our SEM experimental studies are presented in Figure 5 (1A, 2A, 3A -unmodified composites, $1 \mathrm{~B}, 2 \mathrm{~B}, 3 \mathrm{~B}$ - modified with MAPP composites). Looking over SEM pictures, replicas of the fracture surface of unmodified material samples (1A, 2A, 3A) partially or completely uncovered fibre particles are observed. That indicates poor interfacial interaction between fillers and polypropylene. Fracture mechanism examination has shown prominent fiber pull-out from polymer matrix. Besides, fiber and fine particles distribution in polymer is irregular.

Coupling agent MAPP additives strengthen border between fibres and polypropylene $(1 \mathrm{~B}, 2 \mathrm{~B}, 3 \mathrm{~B})$ that provides evidence that interface surface partially is broken only in the case of the coarse fibres, but fine particles in polymer matrix hold well. Furthermore, the structure and sizes of pulled microfibrils are smaller (1-2 microns) 

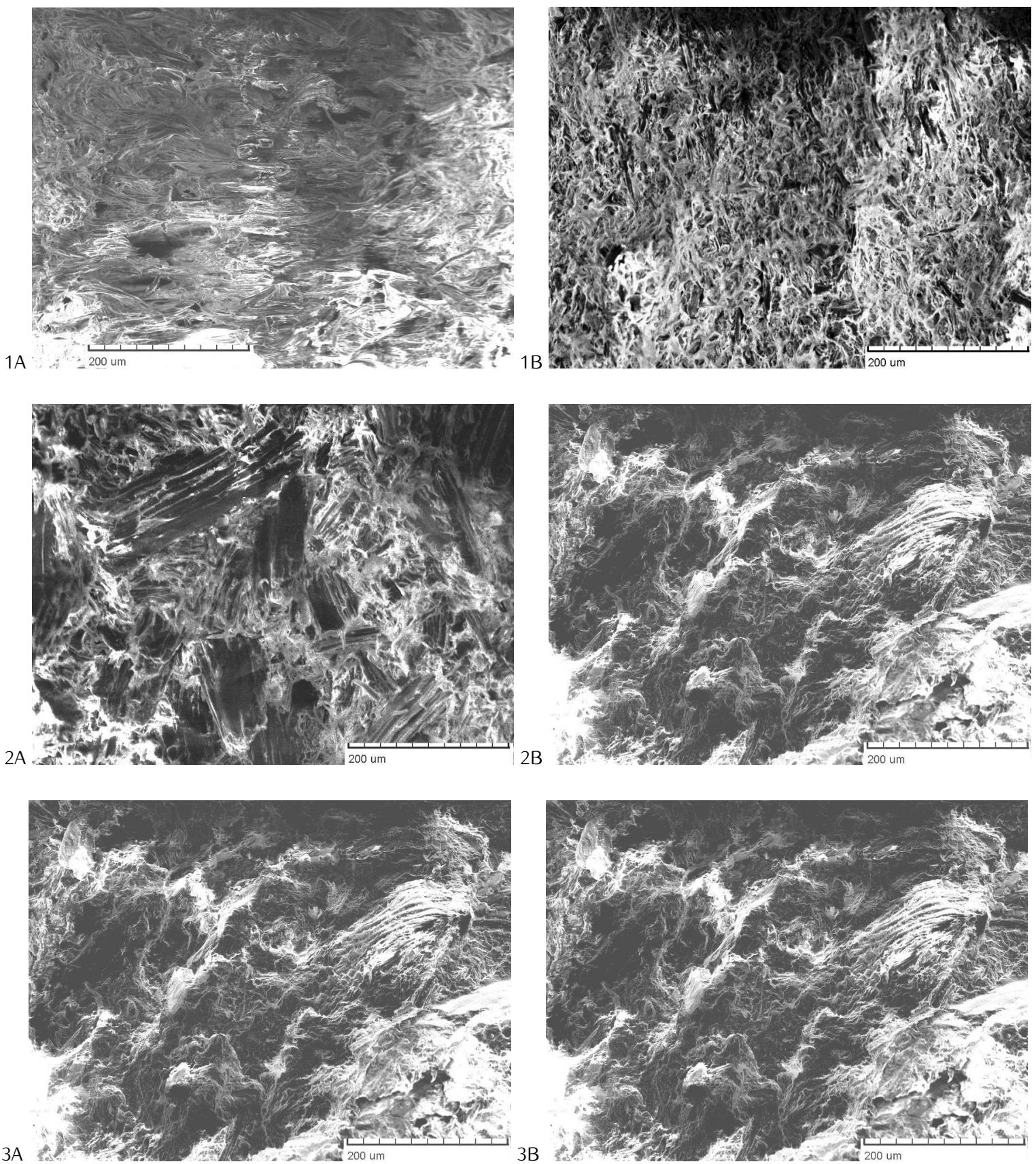

Figure 5. Scanning electron microscopy pictures (SEM) of the fracture surface of specimens made from different composites: $1 A-P P+40$ wt. $\%$ PSD, 1B- PP+40wt. \% PSD + 5 wt. \% MAPP, 2A- PP +50 wt. \% PSWD, 2B- PP+50 wt. \% PSWD +5 wt.\% MAPP, 3A- PP +50 wt. \% RPSF, 3B- PP+50 wt.\% RPSF +5 wt.\% MAPP.

compared to unmodified materials (15-500 microns).

SEM studies once more confirmed the fact of strengthening the interfacial adhesion between wood fillers and PP matrix as a result of the action of the MAPP that evidently gives considerable increase in exploitation properties of the wood polypropylene composites (WPC).

\section{Conclusions}

1. Wood polypropylene composites (WPC) physical mechanical properties studies showed that modification of the composites with interfacial modifier maleated polypropylene waxes (MAPP) 
considerably increases the tensile strength $(2-2.2$ times) and modulus, the flexural strength (1.7-2.2 times) and modulus and the impact strength (1.5-2.2 times) compared to unmodified systems. Simultaneously, deformation ability of materials with increase of MAPP concentration in composites changes insignificantly.

2. Coupling agent maleated polypropylene additions remarkably improve water resistance of all investigated composites. The best water resistance was demonstrated by composites containing plywood sanding dusts and $5 \mathrm{wt} \%$ MAPP.

3. SEM studies confirmed the strengthening effects of the interfacial adhesion between wood fillers and PP matrix as a result of the action of the MAPP that evidently gives considerable increase of exploitation properties of the WPC.

\section{Acknowledgment}

Research has been done by SIA "MNKC" within the project "Forest Sector Competence Centre", which is funded by the agreement No L-KC-11-0004 with Investment and Development Agency of Latvia.

\section{References}

[1] Polyolefin Composites Ed. by Domasius Nwabunma and Thein Kun 3M Company, Wiley-Interscience A. John Wiley and Sons INC Publications, 2007, 3-82, 87-123, 150-201

[2] Ramakrisha M., Kurmar V., Singh Y.N., Recent Development in Natural Fibre reinforced Polypropylene composites, Journal of Reinforced Plastics and Composites, 28, 2009, 1169-1189

[3] Nestore.O., Kajaks J., et al., Physical and mechanical properties of composites based on linear low density (LLDPE) and natural fibre waste, Mechanics of Composite Materials, 48, 2012, No. 6, 616-628

[4] Sobczak L., Lang R.W., Haider A., Polypropylene composites with natural fibers and wood - general mechanical properties, Composites Science and Technology, 72(5), 2012, 550-557
[5] Bulylina S., Mactikka O., Karki T., Properties of wood fibre-polypropylene composites: Effect of wood fibre source, Applied Composite Materials, 18(2), 2011, 101-111

[6] Ashori A., Study on mechanical properties of wood fibre-polypropylene composites, Advanced Materials Research, 123-125, 2010, 1195-1198

[7] Lou C.-W., Lin C.-W., Huang C.-H., Li T.-T., Preliminary study of polypropylene/sawdust green composites, Advanced Materials Research, 557-559, 2012, 334-337

[8] Perez E., Fama L., Pardo S., Tensile and fracture behaviour of PP/wood flour composites, Composites Part B: Engineering, 43(7), 2012, 2795-2800

[9] Kurmar V., Tyagi L., Sinha S., Wood flour reinforced plastic composite: A review, Reviewers in Chemical Engineering, 27(5-6), 2011, 252-264

[10] Mendez I. A., Vilaseca F., Pelach M. A., Evaluation of reinforcing effects of ground wood pulp in the preparation of polypropylene based composites coupled with maleated polypropylene, Journal of Applied Polymer Science, 105 (6), 2007, 3588-3596

[11] Ashori A., Nourbaksh A. Reinforced wood/polypropylene composites: Effects of chemical composition and particle size, Bioresource Technology, 101(7), 2010, 2515-2519

[12] Renner K., Kenyo C., Moczo J., Micromechanical deformation processes in PP/wood composites: particle characteristics, adhesion mechanisms, Composites Part A: Applied Science and Manufacturing, 41(11), 2010, , 1653-1661

[13] Xu Q., Cui Y., Wang X., Xia Z., et al., Moisture absorption properties of wood fiber reinforced recycled polypropylene matrix composites, Journal of Vinyl and Adhesive Technology, 16(1), 2010, 50-57

[14] Thumn A., Dickson A., The influence of fiber length and damage on mechanical performace of polypropylene/wood pulp composites, Composites Part A: Applied Science and Manufacturing, 46, 2013, 45-62

[15] Deng W., Song Y., Wang Q., Wang W., Improvement of compatibility and mechanical properties of modified wood fiber/polypropylene composites, Frontiers of Foresty in China, 3(2), 2008, 243-247 